\title{
Evaluation of chemical additives in hydrothermal pre-treatment of wood for the integrated production of monosugars and hydrolysis lignins for PLA-based biocomposites
}

\author{
Marc Borrega $^{1} \mathbb{D} \cdot$ Ville Pihlajaniemi $^{1} \cdot$ Tiina Liitiä $^{1} \cdot$ Lisa Wikström $^{1} \cdot$ Tarja Tamminen $^{1}$
}

Received: 20 November 2020 / Revised: 26 January 2021 / Accepted: 8 February 2021

(C) The Author(s) 2021

\begin{abstract}
The use of chemical additives (1- and 2-naphthol, formaldehyde) in hydrothermal pre-treatments of pine, birch, and willow wood was evaluated to minimize lignin condensation reactions and consequently improve the saccharification of the pre-treated materials. The residual hydrolysis lignins were then tested in the preparation of polylactic acid (PLA)-based composites. The results showed that addition of 2-naphthol to the hydrothermal pre-treatment increased the saccharification of pine wood by twofold compared to water-only experiments, but the sugar yield was only $50 \%$ of the carbohydrate content in the pre-treated pine. The use of 2-naphthol and formaldehyde also improved somewhat the saccharification of bark-containing willow wood, while the use of 1-naphthol had no effect on the saccharification of any of the pre-treated materials. In birch and willow (without bark), almost complete saccharification could be achieved even without additives. Analyses of hydrolysis lignins from birch revealed structural changes caused by the additives, which were consistent with a reduction of condensation reactions. Selected lignins were successfully used at $20 \%$ loading in PLA/lignin composites; however, variation in mechanical properties among composites prepared with different lignins was only minor. In general, the use of lignin decreased the strength and ductility of PLA but increased the stiffness. Based on these results, the use of additives may only be beneficial in the pre-treatment of pine or other softwoods to improve the sugar yields.
\end{abstract}

Keywords Additives $\cdot$ Composites $\cdot$ Hydrothermal pre-treatment $\cdot$ Lignin $\cdot$ PLA $\cdot$ Saccharification

\section{Introduction}

Hydrothermal treatments are one of the most common pretreatments applied to lignocellulosic biomass to overcome its recalcitrance toward enzymatic saccharification. The main advantages of hydrothermal treatments over other pre-treatment methods are the lower capital costs, the use of water as only solvent, the potential recovery of hemicellulosic sugars, and the low formation of inhibitory compounds that may hinder the subsequent saccharification and/or fermentation process $[1,2]$. Hydrothermal pre-treatments of biomass extensively dissolve the hemicelluloses, which increases the porosity in the cell walls and enhances the accessibility of cellulose to

Marc Borrega

marc.borrega@vtt.fi

1 VTT Technical Research Centre of Finland Ltd., P.O. Box 1000, FI-02044 VTT Espoo, Finland enzymes [3]. Lignin is also partially degraded during the hydrothermal treatment, although the extent of lignin removal is strongly dependent on the particle size of the biomass and on the process parameters $[4,5]$.

The removal of lignin prior to enzymatic hydrolysis is desirable because, in addition to acting as a physical barrier to cellulose, lignin can also inhibit saccharification by nonproductive binding and deactivation of cellulase enzymes, particularly if the lignin has condensed structures $[6,7]$. Lignin condensation during hydrothermal processing occurs when lignin fragments, previously depolymerized through cleavage of the $\beta-\mathrm{O}-4$ bonds, are re-polymerized into the lignin network by reacting with a carbonium ion and forming stable $\mathrm{C}-\mathrm{C}$ linkages [8]. Lignin condensation is enhanced when hydrothermal treatments are performed under high severities [9]. Lignin in softwoods is also more prone to undergo condensation reactions because guaiacyl units, which are abundant in softwoods, have a higher tendency to cross-link than syringyl units, which are abundant in hardwoods. Furthermore, lignin fragments already dissolved in the 
aqueous hydrolysate can condense and precipitate onto the surface of lignocellulosic fibers during cooling of the hydrolysate $[3,10]$.

The condensation of lignin during hydrothermal treatments can be prevented (or minimized) by addition of chemical additives, which act as carbonium ion scavengers. Wayman and Lora (1978) investigated the effect of several aromatic compounds during hydrothermal processing of aspen wood, and found that 2-naphthol was the most effective additive in preventing lignin condensation. Based on their pioneering work, several other researchers have later used 2-naphthol during hydrothermal pre-treatment of biomass, leading to improvements in delignification or saccharification of the pretreated solid residues $[8,11,12]$. Recently, the addition of formaldehyde to a mixture of 1,4-dioxane and hydrochloric acid was also suggested to hinder the formation of $\mathrm{C}-\mathrm{C}$ linkages in the extracted (soluble) lignin, promoting high monomer production after hydrogenolysis [13]. Preserving the native structure of lignin by avoiding condensation reactions during biomass pre-treatments might also enhance the reactivity and/or performance of the lignin in composite material applications. This is because condensed structures with strong intramolecular bonds reduce the molecular mobility of the lignin polymer and negatively affect its compatibility with other polymers [14, 15]. Hydrolysis lignin is a term commonly applied to refer to the lignin-enriched solid residue left after enzymatic hydrolysis of biomass. The economic viability of saccharification and other biorefinery processes is strongly influenced by the ability to further utilize the lignin sidestreams in the manufacture of materials and chemicals [16, 17]. One promising and potential high-volume application for lignin is as filler in polymer composites. Lignin has been studied in blends with polylactic acid (PLA), polypropylene, polyethylene, polyurethane, and several other polymeric matrices with and without fiber reinforcement [18-20]. The use of lignin in composites may require that the lignin is chemically modified to improve the compatibility with the matrix, although coupling agents and compatibilizers can also be utilized for this purpose. Compared to synthetic polymers, the bio-based origin of PLA makes it particularly appealing for the preparation of biocomposites. In general, the addition of lignin to PLA appears to decrease the tensile strength and ductility, but the stiffness remains largely unaffected or even increases up to about $20 \%$ lignin content [21-23]. Lignin can also provide additional functionalities to the composites such as antimicrobial, antibacterial, and antioxidant properties [24-26]. Most of the work on lignin-based composites has been done with lignins obtained from pulping processes, but the use of hydrolysis lignins in PLA/lignin composites remains barely unexplored.

The objectives of this study were to investigate the effects of chemical additives in the hydrothermal pre-treatment of various woods on their subsequent saccharification, and to demonstrate the applicability of residual hydrolysis lignins as filler in PLA/lignin biocomposites with acceptable mechanical properties. The chemical additives 2-naphthol and formaldehyde were selected based on previous literature studies that report their positive effect on preventing condensation reactions in lignin. The additive 1-naphthol, an isomer of 2naphthol, was used for comparison purposes, because 1naphthol was not expected to prevent lignin condensation as repolymerization reactions through the additive are still possible [27]. To our knowledge, 1- or 2-naphthol is not utilized in industrial biorefinery processes, but formaldehyde is one of the key additives in the biomass fractionation process commercialized by the startup company Bloom Biorenewables (Switzerland). Industrially relevant wood species in the Nordic countries such as pine and birch as well as alternative emerging species like willow were selected as lignocellulosic raw materials. The effects of chemical additives on the saccharification of hydrothermally pre-treated woods and on the properties of hydrolysis lignins are here reported. Selected hydrolysis lignins are then used for the preparation of PLA/ lignin composites, and the mechanical properties of the composites are compared.

\section{Experimental}

\subsection{Materials}

Industrial wood chips from birch (Betula spp.) and Scots pine (Pinus sylvestris) were delivered by Stora Enso (Finland). Stems from 2-year-old willow of the variety Tordis $((S$. schwerinii $\times S$. viminalis $) \times S$. viminalis $)$ were delivered by Carbons Finland (Finland). Some of the willow stems were manually debarked with a knife. The wood materials were ground and sieved to obtain wood meal with a particle size between 0.5 and $1 \mathrm{~mm}$ ( $<0.5 \mathrm{~mm}$ for debarked willow). Softwood hydrolysis lignin as residue from biofuel production in pilot scale was provided by St1 (Finland), and softwood kraft lignin was purchased from UPM Biochemicals (Finland).

The chemicals 1-naphthol (99\% purity), 2-naphthol ( $99 \%$ purity), and formalin were purchased from Sigma-Aldrich (Germany). Formalin is a saturated aqueous solution containing 37\% formaldehyde and 10-15\% methanol. Poly(lactic acid) (PLA) for injection molding (3052D grade) was purchased from NatureWorks (USA), epoxidized linseed oil (Lankroflex L ELO) was purchased from Valtris Specialty Chemicals (USA), Vinnex 2525 was purchased from Wacker (Germany), and Dynasylan GLYMO was purchased from Evonik (Germany). Vinnex and Dynasylan are polyvinyl acetate (PVAc) and silane-based additives, respectively. 


\subsection{Hydrothermal pre-treatments}

Hydrothermal pre-treatments of wood meal were conducted in a rotating air-bath digester containing 1-L volume autoclaves (200 $\mathrm{mL}$ for the experiments with formaldehyde). Measured amounts of wood, chemical additive, and water were loaded into each autoclave, reaching a liquid-to-wood ratio of 10:1 $\mathrm{L} / \mathrm{kg}$. The charge of 1- and 2-naphthol was $4.7 \%$ on dry wood mass, while the charge of formaldehyde was $37 \%$ on dry wood mass; these charges were selected based on previous studies $[12,13]$. A series of water-only experiments, i.e., without chemical additives, were also performed as reference. After loading, the autoclaves were purged three times with nitrogen in order to remove oxygen from the system. The temperature was then raised to $200{ }^{\circ} \mathrm{C}$, and thereafter, it was kept constant for 10 to $320 \mathrm{~min}$. The pretreatment intensity including the pre-heating time was calculated with the severity factor $R_{0}$ [28].

Hydrothermal treatments (water-only) of pine, birch, and willow wood were scaled up in a 40-L-volume reactor equipped with a mechanical stirrer. Hydrothermal treatment of pine wood with 2-naphthol as additive was also scaled up. Similar to the small-scale trials, the charge of 2-naphthol was $4.7 \%$ on wood, the reaction temperature was $200{ }^{\circ} \mathrm{C}$, and the liquid-to-wood ratio was 10:1 L/kg.

After the hydrothermal pre-treatments, the aqueous hydrolysates were separated by filtration and the pre-treated solids were thoroughly washed with water. The yield of the pretreated wood materials was calculated on a dry mass basis.

\subsection{Enzymatic hydrolysis}

Enzymatic hydrolysis of the pre-treated solids was carried out in Erlenmeyer flasks with a reaction volume of $100 \mathrm{~mL}$ and a consistency of 5\%, in $50 \mathrm{mM} \mathrm{Na}$-acetate buffer ( $\mathrm{pH}$ 5), using the commercial cellulase mixture Cellic CTec2 (Novozymes) at a dosage of $20 \mathrm{mg}$ of enzyme protein (10.6 filter paper units (FPU) of cellulase activity) per dry gram of pre-treated solid. Na-azide was added to a concentration of $0.2 \mathrm{mg} / \mathrm{mL}$ in order to prevent microbial contamination. The flasks were incubated on a shaker $(150 \mathrm{rpm})$ at $45{ }^{\circ} \mathrm{C}$ for $72 \mathrm{~h}$. The hydrolysates were filtered through filter paper (Whatman 4, GE Healthcare) and collected, and the filtered solids (i.e., hydrolysis lignins) were washed with excess water and freeze-dried. The sugar content in the hydrolysate was determined by colorimetric analysis using the dinitrosalicylic acid essay [29]. The degree of saccharification was then calculated as the ratio of (anhydro) sugars in the hydrolysate to the carbohydrates in the pre-treated solids. In a few cases, the saccharification values were limited to $100 \%$ as the calculated values slightly exceeded this amount.

For the pre-treated solids obtained in the large-scale trials, the enzymatic hydrolysis was carried out in a 10-L stirred reactor following the procedure described above with some modifications. In these trials, the consistency was increased to $10 \%$, and instead of using Na-azide to provide aseptic conditions, a heat treatment was performed instead. The heat treatment consisted in raising the temperature to $90{ }^{\circ} \mathrm{C}$ and then lowering it to below $50{ }^{\circ} \mathrm{C}$ before adding the enzymes. The hydrolysates were collected by filtration, and the residual hydrolysis lignins were washed with water. The yield of hydrolysis lignin was determined on a dry mass basis, and the sugar yield was calculated by difference and used to determine the degree of saccharification.

\subsection{Composition of initial and pre-treated woods}

The carbohydrates and lignin content of the initial wood materials were determined after a two-stage acid hydrolysis. Neutral monosaccharides were quantified by highperformance anion exchange chromatography with pulse amperometric detection (HPAEC-PAD) in a Dionex ICS-3000 (Thermo Fisher Scientific, Waltham, MA, USA) instrument equipped with a CarboPac PA1 column. Losses by degradation of monosaccharides during the two-stage acid hydrolysis were not considered. The acetate content was determined by capillary electrophoresis according to Rovio et al. [30]. The amount of Klason lignin was quantified gravimetrically, and the amount of acid-soluble lignin (ASL) was determined by UV-spectrometry at 215 and $280 \mathrm{~nm}$, using the Goldschmid equation [31]. The extractive content of the starting wood material was determined after extraction with heptane, and the ash content was determined gravimetrically after combustion of the lignin samples at $550^{\circ} \mathrm{C}$ for $23 \mathrm{~h}$ (including heating time). The identified chemical composition of the wood materials is shown in Table 1.

The lignin content of the wood residues from the hydrothermal pre-treatments was determined as the sum of Klason and ASL after a two-stage acid hydrolysis. The carbohydrate content was estimated by subtracting the lignin content from the total mass of pre-treated solids.

\subsection{Analyses of pre-hydrolysates}

The $\mathrm{pH}$ of the aqueous hydrolysates obtained in the hydrothermal pre-treatments was determined after centrifugation to remove insoluble particles. For selected samples, the content of furfural and hydroxymethylfurfural (HMF) was determined by high-performance liquid chromatography in a PerkinElmer Flexar (Waltham, MA, USA) instrument equipped with a Bio-Rad Aminex HPX-87 column, and the total carbohydrate content was determined by HPAEC-PAD after an acid hydrolysis stage. 
Table 1 Identified chemical composition of the wood materials used in this study. Values shown as \% of dry wood

\begin{tabular}{lllll}
\hline & Pine & Birch & Willow (no bark) & $\begin{array}{l}\text { Willow } \\
\text { (with bark) }\end{array}$ \\
\hline Glucose $^{\mathrm{a}}$ & 40.0 & 35.1 & 34.7 & 34.0 \\
Mannose $^{\mathrm{a}}$ & 11.5 & 1.7 & 1.6 & 1.7 \\
Xylose $^{\mathrm{a}}$ & 4.2 & 18.6 & 14.7 & 12.6 \\
Galactose $^{\mathrm{a}}$ & 1.7 & 0.7 & 0.6 & 0.9 \\
Arabinose $^{\mathrm{a}}$ & 1.4 & 0.4 & 0.4 & 0.7 \\
Rhamnose $^{\mathrm{a}}$ & 0.1 & 0.4 & 0.0 & 0.0 \\
Subtotal sugars & 58.9 & 56.9 & 51.9 & 50.0 \\
Klason lignin & 27.3 & 20.5 & 23.0 & 27.7 \\
ASL & 0.2 & 2.3 & 2.5 & 2.4 \\
Subtotal lignin & 27.5 & 22.8 & 25.5 & 30.1 \\
Acetate & 1.3 & 2.8 & 3.2 & 2.7 \\
Extractives & 1.9 & 0.8 & 1.4 & 0.8 \\
Ash & 0.3 & 0.3 & 0.6 & 1.2 \\
Total & 89.8 & 83.6 & 82.5 & 84.8 \\
\hline
\end{tabular}

${ }^{a}$ Monosugars are shown as anhydrosugars; sugar losses during acid hydrolysis are not considered

\subsection{Analyses of hydrolysis lignins}

The chemical composition was determined by HPAEC-PAD after a two-stage acid hydrolysis, similarly as for the chemical composition of the initial and pre-treated wood materials. The molar mass distribution of hydrolysis lignins was determined by size-exclusion chromatography (SEC) in PSS (Polymer Standards Service GmbH, Mainz, Germany) MCX columns (1000 and 100,000 $\AA$ ) with pre-column, using $0.1 \mathrm{M} \mathrm{NaOH}$ as eluent ( $\mathrm{pH} 13,0.5 \mathrm{~mL} / \mathrm{min}$, temperature $25 \mathrm{C}$ ). The molar mass distribution, weight average molar mass $\left(M_{\mathrm{w}}\right)$, and number average molar mass $\left(M_{\mathrm{n}}\right)$ were calculated against polystyrene sulfonate standards $(8 \times$ PSS, $3420-148500 \mathrm{~g} / \mathrm{mol})$ using Waters Empower 3 software. The polydispersity (PD) was calculated as the ratio of $M_{\mathrm{w}}$ to $M_{\mathrm{n}}$.

Phenolic hydroxyls, aliphatic hydroxyls, and carboxylic acids in the hydrolysis lignins were determined by ${ }^{31} \mathrm{P}$ nuclear magnetic resonance (NMR) in a Bruker $500 \mathrm{MHz}$ (Billerica, MA, USA) spectrometer, according to the method developed by Granata and Argyropoulos [32].

\subsection{Preparation of PLA/lignin composites}

The hydrolysis lignins from pine, birch, and willow wood obtained in the large-scale trials were used in the preparation of PLA/lignin composites at $20 \%$ lignin loading. Hydrolysis lignin from pilot scale provided by St1 and industrial-kraft lignin were used as reference lignin materials. Chemithermomechanical pulp (CTMP) fibers were used as reinforcement (at $15 \%$ loading) in a selected compounding trial. The addition of ELO, Vinnex, and Dynasylan as coupling agents and compatibilizers (at 1.5-3\% loading) was also tested.

The composites were first compounded using a mini-scale co-rotating twin-screw extruder (Xplore Instruments BV $\mathrm{MC} 15,15 \mathrm{~cm}^{3}$ ), and then molded using a mini injection molding machine (Thermo-Haake MiniJet type 557-2270) to small dog bone-shaped specimens according to ISO 3167 . The compounding conditions were $190{ }^{\circ} \mathrm{C}, 100 \mathrm{rpm}$, and 2 min mixing time, and the injection molding conditions were temperature at the cylinder, $190{ }^{\circ} \mathrm{C}$; temperature at the mold, $40{ }^{\circ} \mathrm{C}$; injection pressure, 450 bars $(5 \mathrm{~s})$; post pressure 220 bars (10s).

\subsection{Properties of the composites}

Thermogravimetric analyses of the PLA/lignin composites were performed with a differential scanning calorimeter (DSC 204 F1 Phoenix, Netzsch) to observe the transition temperatures and crystallinities of the materials. During the DSC measurements, heating and cooling runs were carried out twice from 0 to $190{ }^{\circ} \mathrm{C}$ with a heating/cooling rate of $10 \mathrm{~K} / \mathrm{min}$.

The morphology of the composites was studied by microscopy using a JEOL JSM-6360LV scanning electron microscope (SEM). The scanning was made on cross-cut surfaces, and the surface of the samples was coated with gold to prevent surface charging.

The tensile mechanical properties of the composites were tested in an Instron 4505 Universal Tensile Tester (Instron Corp., Canton, MA, USA), using a $2 \mathrm{~mm} / \mathrm{min}$ cross-head speed. Five specimens were tested for each sample material to obtain the average values of the tensile properties. The test specimens were kept in standard conditions $\left(23{ }^{\circ} \mathrm{C}, 50 \%\right.$ relative humidity) for at least five days prior to mechanical testing.

\section{Results and discussion}

\subsection{Hydrothermal pre-treatments of wood}

Wood meal from pine, birch, and willow was hydrothermally pretreated at $200{ }^{\circ} \mathrm{C}$ with and without addition of chemical additives (i.e., 1-naphthol, 2-naphthol, and formaldehyde). The yields of pre-treated solid as a function of pre-treatment severity are shown in Fig. 1. In the water-only experiments, the solid yield for pine and willow wood was between 60 and $70 \%$, while the solid yield for birch was between 50 and $60 \%$. The lower yield for birch wood may be partly explained by its higher xylan content (see Table 1), because xylan is extensively removed during hydrothermal treatments at elevated temperatures [33]. In willow, similar 
Fig. 1 Solid yields after hydrothermal pre-treatment of a pine, $\mathbf{b}$ birch, and $\mathbf{c}$ willow milled wood with/without chemical additives. Water, water only; $1 \mathrm{~N}, 1-$ naphthol; 2N, 2-naphthol; FA, formaldehyde. Willow wood was treated with bark unless otherwise specified

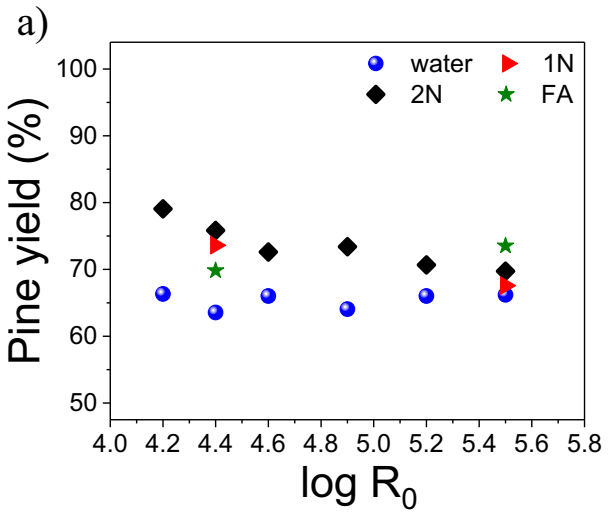

b)

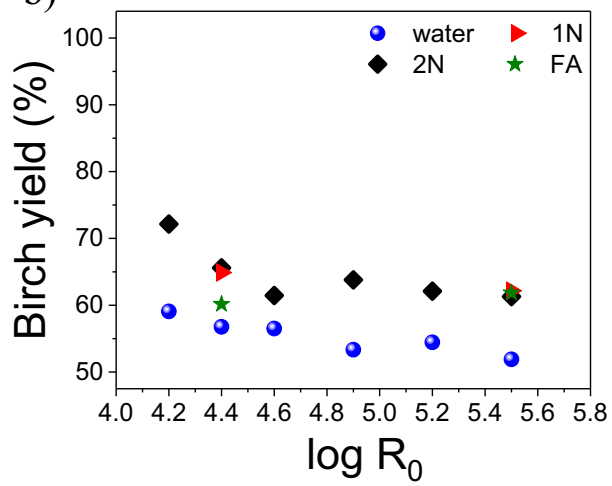

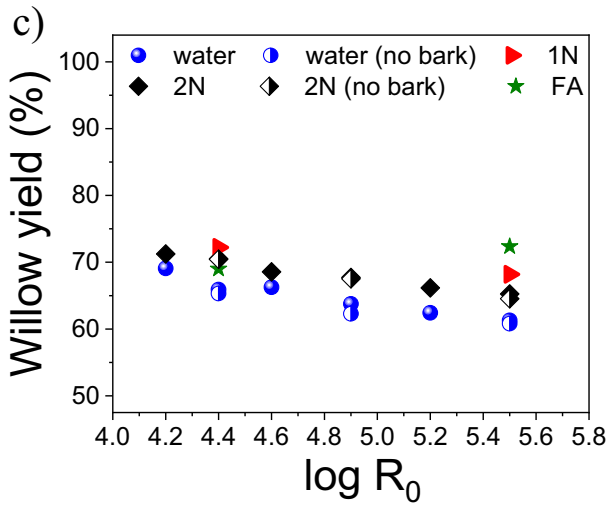

yields were obtained for wood meal with bark (particle size 0.5-1 $\mathrm{mm}$ ) and without bark (particle size $<0.5 \mathrm{~mm}$ ). Compared to water-only experiments, the wood yields after hydrothermal pretreatments with the addition of chemical additives were about 5 $10 \%$ higher for pine and birch, and about 5\% higher for willow (Fig. 1). These higher yields appeared to confirm that the additives were incorporated to some extent into the wood structure.

The $\mathrm{pH}$ of the aqueous hydrolysates from the pretreatments of pine and birch wood with only water or with addition of naphthols was mostly between 3 and 3.5 (Figure $\mathrm{S} 1$ ), which is within the acidity range typically reported for hydrothermal treatment of woods under similar conditions [5, 34]. Interestingly, the $\mathrm{pH}$ of the hydrolysates from willow wood was roughly $\sim 0.5$ units higher, between 3.5 and 4 , and the presence of bark in willow barely had an effect on the acidity of the hydrolysates. Since the amount of acetate in pine was lower than that in birch, and the amounts of acetate in birch and willow were rather similar (see Table 1), any differences in $\mathrm{pH}$ cannot be explained by differences in the formation of acetic acid following the hydrolytic cleavage of acetate groups. The formation of other carboxylic acids as degradation products from monosugars might partly explain the lower $\mathrm{pH}$ in hydrolysates from pine and birch [35]. For all woods, the addition of formaldehyde resulted in hydrolysates with lower $\mathrm{pH}$ (up to 0.5 units) than in the case of water-only or naphthol experiments, most likely due to the oxidation of formaldehyde into formic acid.

\subsection{Enzymatic saccharification of pre-treated woods}

The wood residues from the hydrothermal pre-treatments were thoroughly washed and subjected to enzymatic hydrolysis. As shown in Fig. 2, the saccharification was strongly dependent on the wood material and on the chemical additive used in the hydrothermal pre-treatment. In pine wood, only $20-25 \%$ of the carbohydrates in the pre-treated solids could be hydrolyzed after water-only experiments, but the addition of 2-naphthol increased the saccharification up to $50 \%$ (i.e., about $100 \%$ increase) after $320 \mathrm{~min}$ of pre-treatment time $\left(\log R_{0} 5.5\right)$. The improved saccharification by the addition of 2-naphthol may be explained by a lower extent of lignin condensation in the pre-treated wood, as condensed lignin structures are known to promote non-productive binding of the enzyme to the lignin [6, 7]. Previously, Pielhop et al. also reported that the addition of 2-naphthol to the hydrothermal pre-treatment of spruce wood prevented lignin condensation and increased saccharification by $64 \%$ [12]; however, the degree of saccharification in spruce wood was remarkably high, nearly $100 \%$, compared to the $50 \%$ observed in this study for pine wood. On the other hand, the addition of 1-naphthol or formaldehyde to the hydrothermal pre-treatment did not improve the enzymatic hydrolysis of pine wood (Fig. 2). It appears that, contrary to 2-naphthol, these two additives did not prevent nor minimize lignin condensation reactions during the pre-treatment. 
Fig. 2 Enzymatic saccharification after hydrothermal pre-treatment of a pine, $\mathbf{b}$ birch, and $\mathbf{c}$ willow milled wood with/without chemical additives. Water, water only; 1N, 1naphthol; 2N, 2-naphthol; FA, formaldehyde. Willow wood was treated with bark unless otherwise specified. The saccharification was calculated with respect to the carbohydrate fraction in the pretreated materials, and was limited to $100 \%$ even if some values slightly exceeded this amount a)

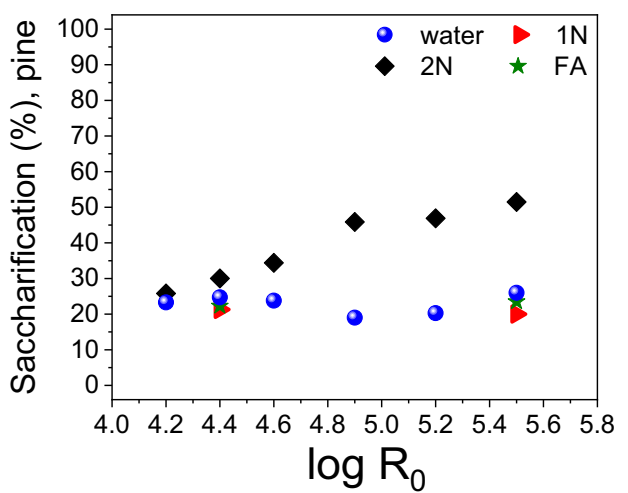

c)

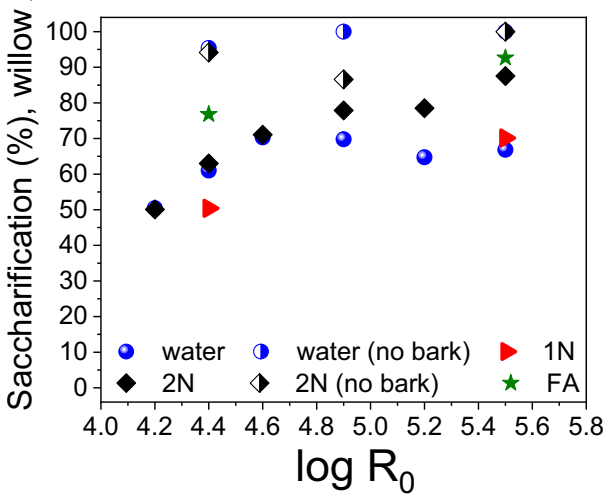

b)

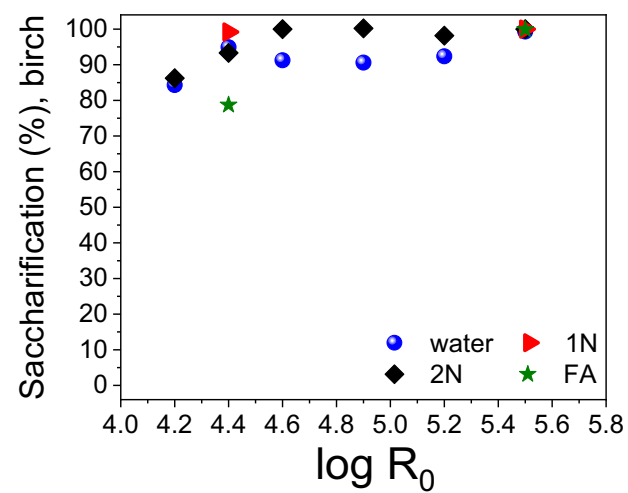

In birch and willow wood, almost quantitative (> 90\%) saccharification could be achieved even after relatively mild pre-treatment severities $\left(\log R_{0} 4.4\right)$, and thus, the addition of chemical additives had little effect on improving enzymatic hydrolysis, even if lignin condensation was prevented by the additives (Fig. 2). In willow, the presence of bark clearly inhibited saccharification, but the addition of 2-naphthol or formaldehyde increased it from $60-70 \%$ to about $90 \%$ at the highest pre-treatment severity $\left(\log R_{0} 5.5\right)$. As with pine, the use of 1-naphthol in hydrothermal pre-treatments did not have any effects on enzymatic hydrolysis compared to water-only experiments, regardless of the wood material.

\subsection{Sugar yields from integrated pre-treatment and saccharification}

The sugar yields obtained by enzymatic saccharification of selected pre-treated woods are shown in Table 2. Despite the significant increase in saccharification of pine wood by the addition of 2-naphthol to the hydrothermal pre-treatment (at $\log R_{0} 5.5$ ), the sugar yield was only $16 \%$ on initial dry wood, or about $27 \%$ of the total carbohydrate content in wood. Low sugar yields are typically obtained from pine wood without addition of acidic catalysts to the pre-treatment prior to saccharification $[36,37]$. The difficulties in obtaining high monomeric sugars yields from softwoods and particularly from pine are often ascribed to their rigid structure and their high lignin content [38]. The inhibitory affinity between lignin and cellulolytic enzymes is known to correlate with the pretreatment severity and the resulting condensed lignin structures, which are particularly abundant in softwoods [39].

The enzymatic sugar yields from birch and willow were about $35-40 \%$ on dry wood without addition of chemical additives (Table 2), which corresponded to $60-75 \%$ of the total carbohydrate content in wood. These sugar yields were slightly higher than the glucose content in birch and willow wood shown in Table 1, but as mentioned before, sugar losses during acidic hydrolysis of wood for the determination of the carbohydrate content were not considered, and thus, the glucose contents in Table 1 are somewhat underestimated. Moreover, the sugar yields shown in Table 2 may also include small amounts of other monosugars than glucose. In willow with bark, the addition of 2-naphthol or formaldehyde to the hydrothermal pre-treatment (at $\log R_{0} 5.5$ ) increased the sugar yield from 20 to $25-30 \%$ on dry wood, still lower than the $40 \%$ obtained for willow without bark and without additives. Therefore, the use of willow wood for the sugar route seems to be justified if suitable debarking methods are developed.

The sugar yields obtained in the hydrothermal pretreatment are also listed in Table 2 to show the potential recovery of sugars along the integrated pre-treatment and saccharification process. Moreover, sugar-based products such as 
Table 2 Yield of sugars, furfural, and HMF obtained during hydrothermal pre-treatment (HT) and enzymatic saccharification of wood for selected pretreatment intensities. Values are shown as \% on initial dry wood

\begin{tabular}{|c|c|c|c|c|c|c|}
\hline Wood material & Chemical additive & HT severity factor $\left(\log R_{0}\right)$ & Sugars, enzymatic (\%) & Sugars, HT (\%) & Furfural, HT (\%) & HMF, HT (\%) \\
\hline Pine & - & 5.5 & 7.6 & 1.1 & 1.1 & 3.2 \\
\hline Pine & $2 \mathrm{~N}$ & 5.5 & 16.2 & 1.1 & 1.0 & 3.2 \\
\hline Pine & $1 \mathrm{~N}$ & 5.5 & 6.2 & 1.0 & 0.9 & 2.6 \\
\hline Pine & FA & 5.5 & 6.4 & 1.9 & 0.9 & 3.1 \\
\hline Birch & - & 4.4 & 35.6 & 11.6 & 4.0 & 0.4 \\
\hline Birch & $2 \mathrm{~N}$ & 4.4 & 38.7 & 11.6 & 3.7 & 0.4 \\
\hline Birch & $1 \mathrm{~N}$ & 4.4 & 41.8 & 10.4 & 4.0 & 0.3 \\
\hline Birch & FA & 4.4 & 32.8 & 8.7 & 3.1 & 0.3 \\
\hline Willow & - & 4.4 & 39.5 & 8.0 & na & na \\
\hline Willow & $2 \mathrm{~N}$ & 4.4 & 39.0 & 8.1 & na & na \\
\hline Willow (with bark) & - & 5.5 & 19.2 & 0.2 & 1.0 & 1.0 \\
\hline Willow (with bark) & $2 \mathrm{~N}$ & 5.5 & 24.3 & 0.2 & na & na \\
\hline Willow (with bark) & $1 \mathrm{~N}$ & 5.5 & 20.4 & 0.2 & na & na \\
\hline Willow (with bark) & FA & 5.5 & 28.0 & 0.2 & na & na \\
\hline
\end{tabular}

IN 1-naphthol, 2N 2-naphthol, FA formaldehyde, na not available

furfural and HMF in the pre-hydrolysates were also quantified because these furanic compounds, formed by dehydration of C5 and C6 monosugars, respectively, are valuable building blocks used in the production of chemicals, plastics, and other industrial applications [40]. In the case of pine and willow with bark, sugar yields lower than $2 \%$ were obtained after $320 \mathrm{~min}$ at $200^{\circ} \mathrm{C}\left(\log R_{0} 5.5\right)$, with glucose being the main monosugar identified (Table $\mathrm{S} 1$ ). This low sugar recovery was obviously due to the harsh pre-treatment conditions used, which caused severe degradation of the dissolved sugars [9, 41]. The degradation of sugars was further confirmed by the relatively high amount of $\mathrm{HMF}(\sim 3 \%)$ formed by dehydration of C6 sugars (i.e., glucose, mannose) present in glucomannan, the main hemicellulose in pine wood.

In the case of birch and willow (no bark), $8-12 \%$ of sugars was found in the aqueous pre-hydrolysates after $20 \mathrm{~min}$ of reaction time ( $\log R_{0} 4.4$; Table 2$)$. As expected, xylose was the main sugar identified (Table S1). The recovery of xylose from birch was slightly higher than from willow, probably related to the higher xylan content in birch wood (18\% vs $15 \%$ on dry wood). About $4 \%$ of furfural was also found in the pre-hydrolysates from birch, which indicated that considerable degradation of xylose occurred under such pretreatment conditions. It is likely that a wide range of lowmolar-mass carboxylic acids was also formed by hydrothermal degradation of sugars. However, except for acetic acid, their amount is typically lower than $2 \%$ on dry wood [35].

To summarize, the use of chemical additives did not affect the yield of sugar and sugar-based compounds obtained in the hydrothermal pre-treatment of pine, birch, and willow wood. The use of 2-naphthol, however, increased the enzymatic saccharification of pine by twofold after severe pre-treatment conditions ( $\log R_{0} 5.5$ ), probably because lignin condensation in the pre-treated wood was prevented by the additive. Despite the improved saccharification, the sugar yield was only $16 \%$ on initial dry wood (or $27 \%$ of the carbohydrate content). Therefore, the addition of an acidic catalyst to the pretreatment is still needed to overcome the recalcitrance of pine wood to enzymatic hydrolysis. It is worth considering, however, that if severe pre-treatment conditions are needed for effective saccharification, the potential gain in sugar yield by enzymatic hydrolysis may be offset by the loss in sugar yield by hydrothermal pre-treatment. With respect to the other woods tested in this study, the use of 2-naphthol as well as formaldehyde in the hydrothermal pre-treatment also enhanced the saccharification of bark-containing willow wood, while chemical additives had only a negligible effect on the saccharification of birch and willow without bark, and thus, their use would not be justified.

\subsection{Composition and structure of hydrolysis lignins}

The hydrolysis lignins obtained as residue from enzymatic hydrolysis of wood, pre-treated with a severity factor of $\log$ $R_{0} 4.4$ (for birch and willow without bark) or $\log R_{0} 5.5$ (for pine and willow with bark), were analyzed to identify any potential differences in their composition and structure derived from the use of chemical additives (Table S2). In general, the lignin content in the hydrolysis lignins was the highest for birch, followed by willow without bark, willow with bark, and finally the pine lignins. The chemical composition of the hydrolysis lignins was obviously related to the efficiency of 
saccharification for those materials under the selected pretreatment conditions (see Fig. 2). Unfortunately, most of the hydrolysis lignins still contained a high amount of carbohydrates, up to $30-40 \%$ in the case of pine lignins, which hindered sample dissolution for the analytical determination of molar mass (by SEC) and lignin functionalities (by ${ }^{31} \mathrm{P}-$ NMR). For this reason, only the hydrolysis lignins obtained by hydrothermal pre-treatment of birch without additives or with addition of naphthols were further analyzed.

As shown in Table 3, the hydrolysis birch lignins obtained from the experiments with 1- and 2-naphthol had a 10-15\% lower molar mass than the hydrolysis lignin from the wateronly experiments. The lower molar mass may be explained by the incorporation of the naphthols to the lignin structure during the hydrothermal pre-treatment, which prevented lignin re-polymerization by cross-linking (condensation) reactions. However, the more prominent effect of 1-naphthol on reducing the molar mass, compared to 2-naphthol, was somewhat surprising because 1-naphthol was expected to allow partial re-polymerization of lignin through the additive [27]. Moreover, the positive effect of 1-naphthol on preventing lignin condensation in birch wood was not apparently replicated in pine wood, at least based on the results from enzymatic hydrolysis (see Fig. 2). It is possible that 1-naphthol did not have the same reactivity with pine as with birch wood due to their different lignin structure.

The lower extent of lignin condensation by the use of naphthols, as indicated by molar mass values, was also supported by the lower amount of substituted C5 units (Table 3). On the other hand, the use of 1-naphthol decreased the amount of carboxylic acid groups, while 2-naphthol clearly increased the amount of guaiacyl units. Signals from the naphthol attached to lignin may, however, partly overlap with the lignin guaiacyl units. The presence of free naphthol was also detected based on the sharp peaks in the p-hydroxyphenyl region, whose assignment was confirmed by model compounds (see

Table 3 Chemical, molecular, and structural properties of hydrolysis lignins from birch treated at $200{ }^{\circ} \mathrm{C}$ for $20 \min \left(\log R_{0} 4.4\right)$

\begin{tabular}{llll}
\hline & Only water & 1-Naphthol & 2-Naphthol \\
\hline Lignin (\%) & 91.4 & 87.6 & 99.0 \\
Sugars (\%) & 5.2 & 9.4 & 2.4 \\
Mw (g/mol) & 7900 & 6700 & 7100 \\
Aliphatic OH (mmol/g) & 2.22 & 2.37 & 2.14 \\
COOH (mmol/g) & 0.14 & 0.08 & 0.16 \\
Phenolic OH (mmol/g) & 2.18 & 2.16 & 2.55 \\
Substituted C5 & 1.70 & 1.56 & 1.63 \\
Guaiacyl & 0.45 & 0.44 & 0.67 \\
p-OH-phenyl & 0.03 & 0.16 & 0.25 \\
Total OH (mmol/g) & 4.54 & 4.61 & 4.85 \\
\hline
\end{tabular}

Figure S2). The amounts of free 1- and 2-naphthol in the hydrolysis lignins corresponded to about $0.43 \%$ and $0.85 \%$ on initial dry wood, respectively.

\subsection{Scale-up production of hydrolysis lignins}

Selected pre-treatment and saccharification experiments were scaled up to produce larger quantities of hydrolysis lignins, as required for the preparation of PLA/lignin biocomposites. Based on the results obtained in the small-scale trials, the pre-treatments selected for scaling up were those corresponding to the hydrothermal pre-treatment of pine with and without addition of 2-naphthol $\left(\log R_{0} 5.5\right)$, birch without additives $\left(\log R_{0} 4.4\right)$, and willow with bark and without additives $\left(\log R_{0} 5.5\right)$. The yield of pre-treated solids and the $\mathrm{pH}$ of the hydrolysates were similar in the small- and large-scale trials, confirming the reproducibility of the pre-treatment (Table 4). However, the sugar yields after enzymatic hydrolysis were lower when the integrated pre-treatment and saccharification process was performed at a large scale. This effect was particularly evident for pine wood pre-treated with 2naphthol and for willow wood (with bark). In pine wood, contrary to the small-scale trials, the addition of 2-naphthol did not improve the saccharification compared to water-only experiments. The lower sugar yields in the large-scale trials may be explained by the higher consistency ( $10 \%$ instead of $5 \%$ ) used in the saccharification step, as previously observed by other authors $[42,43]$. It is also possible that differences in sugar yields were related to the calculation method. In the small-scale trials, the sugar yield was calculated using the dinitrosalicylic acid essay, while in the large-scale trials, it was calculated by the difference from the yield of hydrolysis lignin. The lower sugar yields in the large-scale trials obviously resulted in higher yields of hydrolysis lignins, with an actual lignin content between 55 and 75\% (Table 4). The purity of the hydrolysis lignin from birch was considerably lower than that in the small-scale experiments.

\subsection{PLA/lignin composites}

The hydrolysis lignins from pine, birch, and willow wood produced at a large scale were used in the preparation of PLA/lignin composites at $20 \%$ loading. The hydrolysis lignins differed from their carbohydrate content (see Table 4), and presumably also in their structure due to the different wood material and pre-treatment conditions. In addition to these experimental lignin materials, a softwood hydrolysis lignin from pilot-scale production of biofuels $(\sim 26 \%$ carbohydrate content) and an industrial softwood kraft lignin $(\sim 2 \%$ carbohydrate content) were also used as references.

The mechanical properties of the PLA/lignin composites are shown in Table 5. The PLA/lignin composites exhibited lower tensile strength and ductility but somewhat higher 
Table 4 Yield of hydrothermally pre-treated woods and yield and composition of hydrolysis lignins from small- and large-scale trials

\begin{tabular}{|c|c|c|c|c|c|c|c|c|}
\hline \multirow[b]{2}{*}{ Scale of experiments } & \multicolumn{2}{|l|}{ Pine } & \multicolumn{2}{|l|}{ Pine $2 \mathrm{~N}$} & \multicolumn{2}{|l|}{ Birch } & \multicolumn{2}{|c|}{ Willow (with bark) } \\
\hline & Small & Large & Small & Large & Small & Large & Small & Large \\
\hline $\log R_{0}$ & 5.5 & 5.5 & 5.5 & 5.5 & 4.4 & 4.4 & 5.5 & 5.5 \\
\hline Additive & No & No & 2-Naphthol & 2-Naphthol & No & No & No & No \\
\hline Yield of pre-treated solid ( $\%$ on wood) & 66.2 & 64.7 & 69.7 & 65.8 & 56.8 & 57.7 & 61.3 & 60.3 \\
\hline $\mathrm{pH}$ hydrolysate & 3.0 & 3.1 & 3.0 & 2.9 & 3.1 & 3.0 & 3.7 & 3.8 \\
\hline Enzymatic sugar yield (\% on wood) & 7.6 & 4.8 & 16.2 & 5.2 & 35.6 & 31.8 & 19.2 & 7.9 \\
\hline Yield of hydrolysis lignin (\% on wood) & 58.6 & 59.9 & 53.6 & 60.6 & 21.2 & 25.9 & 42.1 & 52.4 \\
\hline Sugar content (\% on hydrolysis lignin) & 35.6 & 35.9 & 28.1 & 30.2 & 5.2 & 20.0 & 24.6 & 28.1 \\
\hline Lignin content ( $\%$ on hydrolysis lignin) & 59.5 & 58.5 & 67.3 & 64.5 & 91.4 & 73.3 & 71.3 & 65.2 \\
\hline
\end{tabular}

stiffness compared to pure PLA, in agreement with previous studies on the mechanical performance of PLA/lignin composites with lignin contents above $5 \%[21,22,44]$. The composites prepared with hydrolysis lignins from pine appeared to have a slightly higher stiffness, which may have been related to the higher carbohydrate content of those lignins. On the other hand, the addition of 2-naphthol to the hydrothermal pre-treatment of pine had no effects on the mechanical performance of the PLA/lignin composites, even if condensation reactions during the hydrothermal pre-treatment were minimized by the additive. The apparent irrelevance of the lignin structure for the mechanical performance of PLA/lignin composites was further supported by the properties of the composites prepared with kraft lignin. Despite the low carbohydrate content and highly altered and condensed structure of kraft lignin [45], the strength and stiffness of the kraft-based composites were similar to those of the composites prepared with hydrolysis lignin, and only the ductility was noticeably higher (Table 5). In general, the variation in mechanical properties among composites prepared with different lignins was only minor.

The tensile and impact strength of lignin-containing composites typically decreases with increasing lignin loading, resulting in brittle composite materials $[46,47]$. The increased brittleness is assumed to be largely caused by the poor compatibility between lignin and the more hydrophobic polymer matrix [20]. For this reason, compatibilizers are often used to improve the interactions between lignin and the matrix and thus enhance the mechanical performance of the composites. In this study, epoxidized linseed oil (ELO) was tested as a novel and bio-based plasticizing coupling agent to improve the lignin processability and to chemically connect lignin to

Table 5 Mechanical properties of PLA/lignin composites (20\% lignin content), without or with compatibilizers (ELO, Vinnex, and GLYMO)

\begin{tabular}{|c|c|c|c|c|c|c|}
\hline Sample & PLA $(\%)$ & Lignin $(\%)$ & Other $(\%)$ & Young's modulus (GPa) & Tensile strength (MPa) & Ductility (\%) \\
\hline PLA & 100 & - & - & $3.6^{\mathrm{a}}$ & $61 \pm 2$ & $5.8 \pm 1.7$ \\
\hline PLA/HL birch & 80 & 20 & - & $3.7 \pm 0.1$ & $51 \pm 1$ & $1.8 \pm 0.3$ \\
\hline PLA/HL willow & 80 & 20 & - & $3.9 \pm 0.2$ & $54 \pm 1$ & $1.9 \pm 0.1$ \\
\hline PLA/HL pine & 80 & 20 & - & $4.3 \pm 0.3$ & $56 \pm 1$ & $1.9 \pm 0.2$ \\
\hline PLA/HL pine $2 \mathrm{~N}$ & 80 & 20 & - & $4.2 \pm 0.2$ & $55 \pm 2$ & $1.9 \pm 0.1$ \\
\hline PLA/HL ref & 80 & 20 & - & $3.8 \pm 0.4$ & $48 \pm 5$ & $1.5 \pm 0.3$ \\
\hline PLA/Kraft ref & 80 & 20 & - & $3.5 \pm 0.1$ & $56 \pm 1$ & $3.3 \pm 0.8$ \\
\hline PLA/HL ref $0.75 \%$ ELO & 79.25 & 20 & 0.75 & $4.1 \pm 0.5$ & $44 \pm 1$ & $1.5 \pm 0.2$ \\
\hline PLA/HL ref $1.5 \%$ ELO & 78.5 & 20 & 1.5 & $4.2 \pm 0.2$ & $48 \pm 1$ & $1.6 \pm 0.1$ \\
\hline PLA/HL ref $1.5 \%$ Vinnex & 78.5 & 20 & 1.5 & $3.8 \pm 0.1$ & $54 \pm 2$ & $1.8 \pm 0.1$ \\
\hline PLA/HL ref $1.5 \%$ Dynasylan & 78.5 & 20 & 1.5 & $4.1 \pm 0.3$ & $49 \pm 1$ & $1.7 \pm 0.1$ \\
\hline PLA/HL ref 3\% ELO & 77 & 20 & 3 & $4.2 \pm 0.4$ & $46 \pm 1$ & $1.8 \pm 0.1$ \\
\hline PLA/Kraft 3\% ELO & 77 & 20 & 3 & $3.5 \pm 0.2$ & $52 \pm 1$ & $1.7 \pm 0.0$ \\
\hline PLA/HL ref CTMP & 65 & 20 & 15 & $6.1 \pm 0.7$ & $48 \pm 2$ & $1.0 \pm 0.0$ \\
\hline
\end{tabular}

${ }^{\mathrm{a}}$ Value from manufacturer 
a)

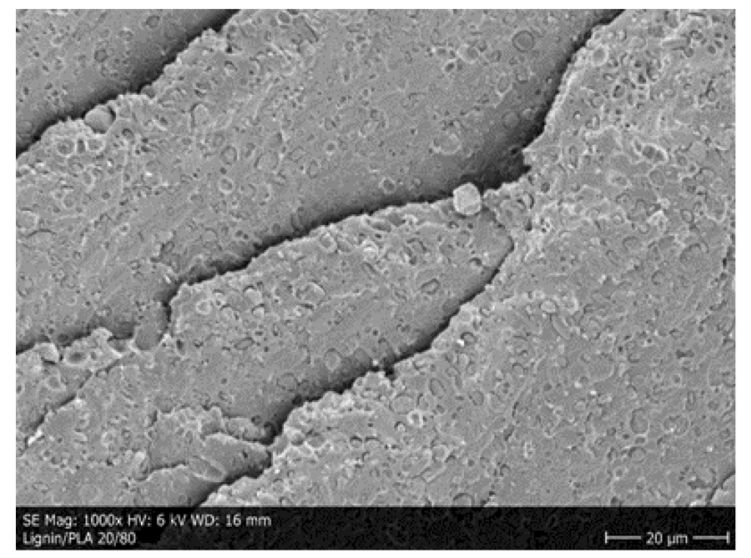

c)

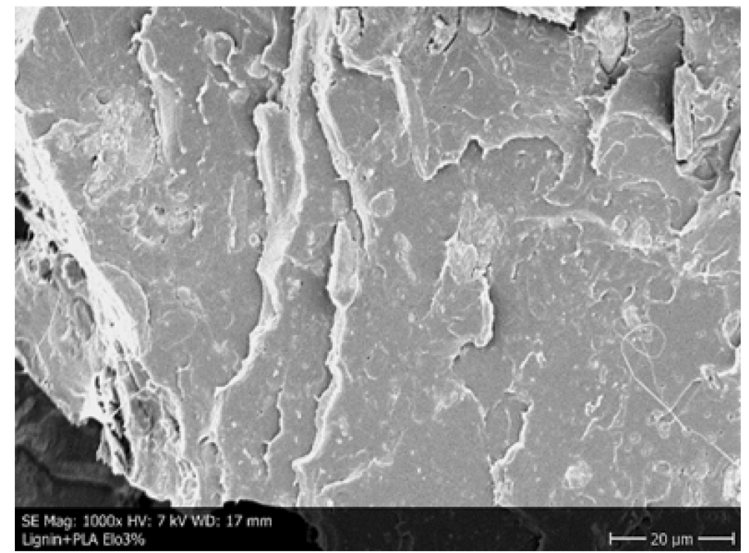

b)

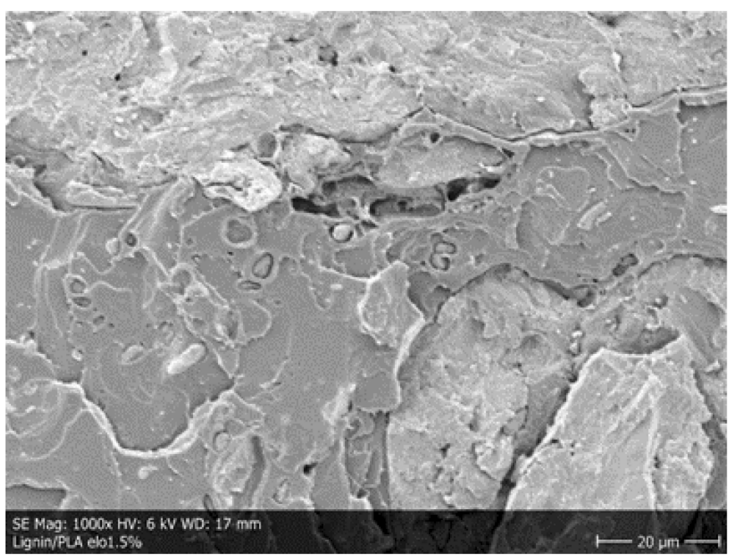

Fig. 3 SEM images $(\times 1000)$ of PLA and hydrolysis lignin (HL ref) composites at $20 \%$ lignin loading a without compatibilizer, b with $1.5 \%$ ELO, and c with $3 \%$ ELO

the PLA matrix. ELO has previously been shown to improve the mechanical properties of PLA biocomposites through better connection with pulp fibers [48, 49]. For comparison, the commercial additives Vinnex and Dynasylan were also tested, using the hydrolysis lignin from pilot scale as reference lignin material.

As shown in Table 5, the addition of coupling agents and compatibilizers had no beneficial effects on the tensile strength nor strain of the composites. This was also observed when kraft lignin was used, which had a higher content of phenolic units available for coupling reactions. The tensile strength could not be improved even with the use of CTMP fibers (15\% loading) as reinforcement, although the use of fibers provided a pronounced increase in stiffness. Nonetheless the small molecular size of the coupling agents and compatibilizers plasticized both the lignin and PLA, which clearly improved the processability. The composites were easier to remove from the mold, and the post-cleaning was also improved.

Scanning electron microscope (SEM) images of the composites were taken to further elucidate the effect of ELO on the compatibility between PLA and lignin. The
Table 6 DSC results from the second heating cycle of PLA/ lignin composites (20\% lignin content), showing the glass transition temperature $\left(T_{\mathrm{g}}\right)$, crystallization temperature $\left(T_{\mathrm{c}}\right)$, melting temperature $\left(T_{\mathrm{m}}\right)$, enthalpy of cold crystallization $(\Delta \mathrm{Hc})$ and enthalpy of melting $(\Delta \mathrm{Hm})$

\begin{tabular}{lllllll}
\hline Sample & $\operatorname{Tg}\left({ }^{\circ} \mathrm{C}\right)$ & $\operatorname{Tc}\left({ }^{\circ} \mathrm{C}\right)$ & $\operatorname{Tm}\left({ }^{\circ} \mathrm{C}\right)$ & $\operatorname{Tm} 2\left({ }^{\circ} \mathrm{C}\right)$ & $\Delta \mathrm{Hc}(\mathrm{J} / \mathrm{g})$ & $\Delta \mathrm{Hm}(\mathrm{J} / \mathrm{g})$ \\
\hline PLA & 58.6 & 119.2 & 150.3 & na & 30.8 & 30.5 \\
PLA/HL & 58.2 & 126.7 & 150.7 & na & 12.1 & 12.0 \\
PLA/HL ref 1.5\% ELO & 55.8 & 116.1 & 148.3 & 153.0 & 24.4 & 23.5 \\
PLA/HL ref 3\% ELO & 53.6 & 116.9 & 147.8 & 152.9 & 27.8 & 27.1 \\
\hline
\end{tabular}

na not available 
images revealed that the reference hydrolysis lignin was not fully compatible with the PLA matrix, as phase separation and a clear discontinuity in the matrix could be seen between lignin and PLA (Fig. 3). However, the lignin compatibility with PLA was clearly improved with increasing the ELO content, thus confirming that ELO acted as a plasticizer, improving the miscibility and processability of the composites. Owing to the plasticizing effect, a clear reduction of the glass transition temperature of PLA from $58.6{ }^{\circ} \mathrm{C}$ up to $53.6{ }^{\circ} \mathrm{C}$ was detected with increasing the ELO content (Table 6). Moreover, the crystallization temperature of PLA (119 ${ }^{\circ} \mathrm{C}$ ) increased with lignin $\left(127^{\circ} \mathrm{C}\right)$ but decreased again with ELO $\left(116^{\circ} \mathrm{C}\right)$. The effect of ELO on the thermal properties of composites is in line with previous studies on PLA-based composites [48, 49]. Based on these results, the addition of various coupling agents in different ratios and dosing protocols should still be tested, and the mechanical performance of the composites should also be confirmed at a larger scale by impact strength measurements.

\section{Conclusions}

The chemical additives 1-naphthol, 2-naphthol, and formaldehyde were used in hydrothermal pre-treatments of wood to minimize lignin condensation reactions and consequently improve the saccharification of the pretreated materials. From those additives, only 2-naphthol may be used to improve the saccharification of pine wood, provided that the cost of adding the additive in the pre-treatment is compensated by the increase in sugar yield. Moreover, from an environmental point of view, an alternative bio-based phenolic compound with similar effects as 2-naphthol should preferably be found. The use of chemical additives is not justified in the pretreatment of hardwoods because quantitative saccharification can be achieved after a water-only hydrothermal pre-treatment. Willow is a suitable wood material for the sugar route as long as debarking methods are developed, as the presence of bark partly inhibits saccharification and probably hinders the subsequent fermentation of released sugars. The residual hydrolysis lignins after saccharification can be used as filler in the preparation of PLA-based biocomposites, with up to $20 \%$ lignin loading. Differences in lignin composition and structure do not seem to affect the performance of the composites. In general, the addition of lignin to PLA slightly decreases the strength but increases the stiffness, and may also introduce relevant functionalities (i.e., antioxidant activity) to the composites. The compatibility of lignin with PLA can be enhanced by the addition of bio-based coupling agents, which also improve the processability. The use of lignin in biocomposites is a promising valorization pathway to increase the profitability of lignocellulosic biorefineries.

Supplementary Information The online version contains supplementary material available at https://doi.org/10.1007/s13399-021-01365-5.

Acknowledgements Business Finland is acknowledged for funding the project "Lignin First Concept for High Value Applications" via the BioNets program. Juha Haakana, Atte Mikkelson, Riitta Alander, Mariitta Svanberg, Jarna Teikari, Tommi Virtanen, Pia WillbergKeyriläinen, Markus Nikinmaa, Sini-Tuuli Rauta, Enni Luoma, and Juha Mannila are thanked for their skillful support with the hydrothermal pre-treatments, enzymatic hydrolysis trials, chemical and structural analyses, and composite preparation.

Funding Open access funding provided by Technical Research Centre of Finland (VTT).

Open Access This article is licensed under a Creative Commons Attribution 4.0 International License, which permits use, sharing, adaptation, distribution and reproduction in any medium or format, as long as you give appropriate credit to the original author(s) and the source, provide a link to the Creative Commons licence, and indicate if changes were made. The images or other third party material in this article are included in the article's Creative Commons licence, unless indicated otherwise in a credit line to the material. If material is not included in the article's Creative Commons licence and your intended use is not permitted by statutory regulation or exceeds the permitted use, you will need to obtain permission directly from the copyright holder. To view a copy of this licence, visit http://creativecommons.org/licenses/by/4.0/.

\section{References}

1. Alvira P, Tomás-Pejó E, Ballesteros M, Negro MJ (2010) Pretreatment technologies for an efficient bioethanol production process based on enzymatic hydrolysis: a review. Bioresour Technol 101:4851-4861. https://doi.org/10.1016/j.biortech.2009. 11.093

2. Yang B, Tao L, Wyman CE (2018) Strengths, challenges, and opportunities for hydrothermal pretreatment in lignocellulosic biorefineries. Biofuels Bioprod Biorefin 12:125-138. https://doi. org $/ 10.1002 / b b b .1825$

3. Nitsos CK, Matis KA, Triantafyllidis KS (2013) Optimization of hydrothermal pretreatment of lignocellulosic biomass in the bioethanol production process. ChemSusChem 6:110-122. https://doi.org/10.1002/cssc.201200546

4. Yang B, Wyman CE (2004) Effect of xylan and lignin removal by batch and flowthrough pretreatment on the enzymatic digestibility of corn stover cellulose. Biotechnol Bioeng 86:88-98. https://doi. org/10.1002/bit.20043

5. Borrega M, Sixta H (2015) Water prehydrolysis of birch wood chips and meal in batch and flow-through systems: a comparative evaluation. Ind Eng Chem Res 54:6075-6084. https://doi.org/10. 1021/acs.iecr.5b00908

6. Rahikainen JL, Martin-Sampedro R, Heikkinen H, Rovio S, Marjamaa K, Tamminen T, Rojas OJ, Kruus K (2013) Inhibitory effect of lignin during cellulose bioconversion: the effect of lignin chemistry on non-productive enzyme adsorption. Bioresour 
Technol 133:270-278. https://doi.org/10.1016/j.biortech.2013.01. 075

7. Sun S, Huang Y, Sun R, Tu M (2016) The strong association of condensed phenolic moieties in isolated lignins with their inhibition of enzymatic hydrolysis. Green Chem 18:4276-4286. https://doi. org/10.1039/c6gc00685j

8. Li J, Henriksson G, Gellerstedt G (2007) Lignin depolymerization/ repolymerization and its critical role for delignification of aspen wood by steam explosion. Bioresour Technol 98:3061-3068. https://doi.org/10.1016/j.biortech.2006.10.018

9. Borrega M, Nieminen K, Sixta H (2011) Effects of hot water extraction in a batch reactor on the delignification of birch wood. BioResources 6

10. Leschinsky M, Zuckerstätter G, Weber HK, Patt R, Sixta H (2008) Effect of autohydrolysis of Eucalyptus globulus wood on lignin structure. Part 2: Influence of autohydrolysis intensity. Holzforschung 62:653-658. https://doi.org/10.1515/HF.2008.133

11. El Hage R, Chrusciel L, Desharnais L, Brosse N (2010) Effect of autohydrolysis of Miscanthus $\mathrm{x}$ giganteus on lignin structure and organosolv delignification. Bioresour Technol 101:9321-9329. https://doi.org/10.1016/j.biortech.2010.06.143

12. Pielhop T, Larrazábal GO, Studer MH, Brethauer S, Seidel CM, Rudolf von Rohr P (2015) Lignin repolymerisation in spruce autohydrolysis pretreatment increases cellulase deactivation. Green Chem 17:3521-3532. https://doi.org/10.1039/c4gc02381a

13. Shuai L, Amiri MT, Questell-Santiago YM et al (2016) Formaldehyde stabilization facilitates lignin monomer production during biomass depolymerization. Science (80- ) 354:329-333. https://doi.org/10.1126/science.aaf7810

14. Kubo S, Kadla JF (2005) Kraft lignin/poly(ethylene oxide) blends: effect of lignin structure on miscibility and hydrogen bonding. J Appl Polym Sci 98:1437-1444. https://doi.org/10.1002/app.22245

15. Baumberger S, Dole P, Lapierre C (2002) Using transgenic poplars to elucidate the relationship between the structure and the thermal properties of lignins. J Agric Food Chem 50:2450-2453. https:// doi.org/10.1021/jf0113530

16. Ragauskas AJ, Beckham GT, Biddy MJ et al (2014) Lignin valorization: improving lignin processing in the biorefinery. Science (80) 344:1246843. https://doi.org/10.1126/science.1246843

17. Sannigrahi P, Pu Y, Ragauskas A (2010) Cellulosic biorefineriesunleashing lignin opportunities. Curr Opin Environ Sustain 2:383393. https://doi.org/10.1016/j.cosust.2010.09.004

18. Thakur VK, Thakur MK, Raghavan P, Kessler MR (2014) Progress in green polymer composites from lignin for multifunctional applications: a review. ACS Sustain Chem Eng 2:1072-1092. https:// doi.org/10.1021/sc500087z

19. Collins MN, Nechifor M, Tanasă F, Zănoagă M, McLoughlin A, Stróżyk MA, Culebras M, Teacă CA (2019) Valorization of lignin in polymer and composite systems for advanced engineering applications - a review. Int J Biol Macromol 131:828-849. https://doi. org/10.1016/j.ijbiomac.2019.03.069

20. Sen S, Patil S, Argyropoulos DS (2015) Thermal properties of lignin in copolymers, blends, and composites: a review. Green Chem 17:4862-4887. https://doi.org/10.1039/c5gc01066g

21. Li J, He Y, Inoue Y (2003) Thermal and mechanical properties of biodegradable blends of poly(L-lactic acid) and lignin. Polym Int 52:949-952. https://doi.org/10.1002/pi.1137

22. Gordobil O, Delucis R, Egüés I, Labidi J (2015) Kraft lignin as filler in PLA to improve ductility and thermal properties. Ind Crop Prod 72:46-53. https://doi.org/10.1016/j.indcrop.2015.01.055

23. Spiridon I, Tanase CE (2018) Design, characterization and preliminary biological evaluation of new lignin-PLA biocomposites. Int $\mathrm{J}$ Biol Macromol 114:855-863. https://doi.org/10.1016/j.ijbiomac. 2018.03.140

24. Espinoza-Acosta JL, Torres-Chávez PI, Ramírez-Wong B et al (2016) Antioxidant, antimicrobial, and antimutagenic properties of technical lignins and their applications. BioResources 11: 5452-5481. https://doi.org/10.15376/biores.11.2.Espinoza_Acosta

25. Dizhbite T, Telysheva G, Jurkjane V, Viesturs U (2004) Characterization of the radical scavenging activity of lignins - natural antioxidants. Bioresour Technol 95:309-317. https://doi.org/ 10.1016/j.biortech.2004.02.024

26. Domínguez-Robles J, Larrañeta E, Fong ML, Martin NK, Irwin NJ, Mutjé P, Tarrés Q, Delgado-Aguilar M (2020) Lignin/ poly(butylene succinate) composites with antioxidant and antibacterial properties for potential biomedical applications. Int J Biol Macromol 145:92-99. https://doi.org/10.1016/j.ijbiomac.2019.12. 146

27. Wayman M, Lora JH (1978) The effects of 2- naphthol and other aromatic compounds. TAPPI J 61:55-57

28. Overend RP, Chornet E, Gascoigne JA (1987) Fractionation of lignocellulosics by steam-aqueous pretreatments. Philos Trans R Soc London Ser A, Math Phys Sci 321:523-536. https://doi.org/ 10.1098/rsta.1987.0029

29. Miller GL (1959) Use of Dinitrosalicylic Acid Reagent for Determination of Reducing Sugar. Anal Chem 31:426-428. https://doi.org/10.1021/ac60147a030

30. Rovio S, Kalliola A, Sirén H, Tamminen T (2010) Determination of the carboxylic acids in acidic and basic process samples by capillary zone electrophoresis. J Chromatogr A 1217:1407-1413. https://doi. org/10.1016/j.chroma.2009.12.032

31. Goldschmid O (1971) Ultraviolet spectra. In: Sarkanen KV, Ludwig CH (eds) Lignins: occurrence, formation, structure and reactions. John Wiley \& Sons, New York, pp 241-298

32. Granata A, Argyropoulos DS (1995) 2-Chloro-4,4,5,5-tetramethyl1,3,2-dioxaphospholane, a reagent for the accurate determination of the uncondensed and condensed phenolic moieties in lignins. $\mathrm{J}$ Agric Food Chem 43:1538-1544. https://doi.org/10.1021/ jf00054a023

33. Borrega M, Nieminen K, Sixta H (2011) Degradation kinetics of the main carbohydrates in birch wood during hot water extraction in a batch reactor at elevated temperatures. Bioresour Technol 102:10210732. https://doi.org/10.1016/j.biortech.2011.09.027

34. Song T, Pranovich A, Sumerskiy I, Holmbom B (2008) Extraction of galactoglucomannan from spruce wood with pressurised hot water. Holzforschung 62:659-666. https://doi.org/10.1515/HF.2008. 131

35. Borrega M, Niemela K, Sixta H (2013) Effect of hydrothermal treatment intensity on the formation of degradation products from birchwood. Holzforschung 67:871-879. https://doi.org/10.1515/hf2013-0019

36. Du X, Lucia LA, Ghiladi RA (2016) Development of a highly efficient pretreatment sequence for the enzymatic saccharification of loblolly pine wood. ACS Sustain Chem Eng 4:3669-3678. https://doi.org/10.1021/acssuschemeng.6b00198

37. Zhu W, Zhu JY, Gleisner R, Pan XJ (2010) On energy consumption for size-reduction and yields from subsequent enzymatic saccharification of pretreated lodgepole pine. Bioresour Technol 101:27822792. https://doi.org/10.1016/j.biortech.2009.10.076

38. Galbe M, Zacchi G (2002) A review of the production of ethanol from softwood. Appl Microbiol Biotechnol 59:618-628. https:// doi.org/10.1007/s00253-002-1058-9

39. Kellock M, Maaheimo H, Marjamaa K, Rahikainen J, Zhang H, Holopainen-Mantila U, Ralph J, Tamminen T, Felby C, Kruus K (2019) Effect of hydrothermal pretreatment severity on lignin inhibition in enzymatic hydrolysis. Bioresour Technol 280:303-312. https://doi.org/10.1016/j.biortech.2019.02.051

40. Shen G, Andrioletti B, Queneau Y (2020) Furfural and 5(hydroxymethyl)furfural (HMF): two pivotal intermediates for bio-based chemistry. Curr Opin Green Sustain Chem 100384. https://doi.org/10.1016/j.cogsc.2020.100384 
41. Ståhl M, Nieminen K, Sixta H (2018) Hydrothermolysis of pine wood. Biomass Bioenergy 109:100-113. https://doi.org/10.1016/j. biombioe.2017.12.006

42. Wang W, Zhuang X, Yuan Z, Yu Q, Qi W, Wang Q, Tan X (2012) High consistency enzymatic saccharification of sweet sorghum bagasse pretreated with liquid hot water. Bioresour Technol 108:252257. https://doi.org/10.1016/j.biortech.2011.12.092

43. Carrasco C, Baudel HM, Sendelius J, Modig T, Roslander C, Galbe M, Hahn-Hägerdal B, Zacchi G, Lidén G (2010) SO2-catalyzed steam pretreatment and fermentation of enzymatically hydrolyzed sugarcane bagasse. Enzym Microb Technol 46:64-73. https://doi. org/10.1016/j.enzmictec.2009.10.016

44. Spiridon I, Leluk K, Resmerita AM, Darie RN (2015) Evaluation of PLA-lignin bioplastics properties before and after accelerated weathering. Compos Part B Eng 69:342-349. https://doi.org/10. 1016/j.compositesb.2014.10.006

45. Gellerstedt $\mathrm{G}$ (2015) Softwood kraft lignin: raw material for the future. Ind Crop Prod 77:845-854. https://doi.org/10.1016/j. indcrop.2015.09.040
46. Toriz G, Denes F, Young RA (2002) Lignin-polypropylene composites. Part 1: composites from unmodified lignin and polypropylene. Polym Compos 23:806-813. https://doi.org/10.1002/pc.10478

47. Sahoo S, Misra M, Mohanty AK (2011) Enhanced properties of lignin-based biodegradable polymer composites using injection moulding process. Compos Part A Appl Sci Manuf 42:1710 1718. https://doi.org/10.1016/j.compositesa.2011.07.025

48. Immonen K, Anttila U, Wikström L (2019) Coupling of PLA and bleached softwood kraft pulp (BSKP) for enhanced properties of biocomposites. J Thermoplast Compos Mater 32:328-341. https:// doi.org/10.1177/0892705718759387

49. Peltola H, Immonen K, Johansson LS, Virkajärvi J, Sandquist D (2019) Influence of pulp bleaching and compatibilizer selection on performance of pulp fiber reinforced PLA biocomposites. J Appl Polym Sci 136:1-12. https://doi.org/10.1002/app.47955

Publisher's Note Springer Nature remains neutral with regard to jurisdictional claims in published maps and institutional affiliations. 